\title{
A Numerical Model for Simulating Ground Motions for the Korean Peninsula
}

\author{
Sang Whan Han and Hyun Woo Jee * \\ Department of Architectural Engineering, Hanyang University, Seoul 04763, Korea; swhan@hanyang.ac.kr \\ * Correspondence: hyunwoo71@hanyang.ac.kr; Tel.: +82-2-2220-0566
}

Received: 7 January 2020; Accepted: 7 February 2020; Published: 13 February 2020

check for updates

Featured Application: Developing a numerical model for simulating ground motions for low-to-moderate seismic regions such as the Korean Peninsula.

\begin{abstract}
Ground motions are used as input for the response history analyses of a structure. However, the number of ground motions recorded at a site located in low-to-moderate seismic regions such as the Korean Peninsula is few. In this case, artificial ground motions need to be used, which can reflect the characteristics of source mechanism, travel path, and site geology. On 15 November, 2017, the Pohang earthquake, with a magnitude of 5.4 and a focal depth of $9 \mathrm{~km}$, occurred near the city of Pohang. This earthquake caused the most significant economic loss among the earthquakes that occurred in the Korean Peninsula. During the Pohang earthquake, valuable ground motions were recorded at stations distributed in the Korean Peninsula. In this study, a ground motion model is proposed based on ground motions recorded during the 2017 Pohang earthquake. The accuracy of the proposed model is verified by comparing measured and simulated ground motions at 111 recording stations.
\end{abstract}

Keywords: ground motion; earthquake; response history analysis; station; seismicity

\section{Introduction}

The Korean Peninsula is located in stable continental regions about $400 \mathrm{~km}$ from the boundaries of four plates: the Philippine Sea, Pacific, North American, and Eurasian Plates [1,2]. The seismic activity in this region is lower than that in regions located near plate boundaries such as Japan, Indonesia, or the Western United States. However, Korean historical documents reported that big earthquakes with a magnitude of 6 or larger occurred in the peninsula from 2 A.D. to 1904 A.D. [3]. The Pohang earthquake, with a magnitude of 5.4 and focal depth of $9 \mathrm{~km}$, occurred near the city of Pohang, located in the Korean South-East province. This earthquake caused the largest casualties and economic loss among the earthquakes that have occurred in Korea.

To protect structures from earthquakes, it is necessary to conduct the seismic performance evaluation of structures with reliable input ground motions, and to retrofit the structures based on the results of the seismic performance evaluation [4-6]. However, it is difficult to collect available ground motions recorded from mid- to large-size earthquakes that have occurred in sites located in low-to-moderate seismic regions. In this case, artificial ground motions can be simulated and used in seismic performance evaluation. Simulated ground motions should retain the characteristics of the local source mechanism, travel path, and geology of a site.

Previous studies [7-12] have developed and improved the ground motion simulation model to generate artificial ground motions by considering key components of seismological characteristics. Ground motions can be simulated using the stochastic point-source model in the frequency domain and the shaping window model in the time domain. 
In this study, a ground motion simulation model is proposed. The ground motion parameters are determined based on the ground motions recorded from the mainshock of the 2017 Pohang earthquake.

To verify the accuracy of the proposed model, the key components of measured and simulated ground motions are compared, such as peak ground acceleration (PGA) and 5\% damped pseudo spectral acceleration (PSA).

In order to develop the proper ground motion simulation model for the Korean Peninsula, this article is organized into three sections. In Section 2, the collected ground motions in three orthogonal directions (East-West, North-South, and Vertical) are presented, which were recorded from 111 stations in the inland Korean Peninsula during past earthquakes. In Section 3, a stochastic point-source model and shape window model are proposed to simulate the ground motions recorded during past earthquakes that occurred in the Korean Peninsula. In Section 4, the proposed model is verified by comparing the generated artificial ground motions and ground motions recorded during the 2017 Pohang earthquake event.

\section{Ground Motions Collected for Developing the Ground Motion Simulation Model}

To develop a numerical model for simulating ground motions in the Korean Peninsula, the ground motions recorded at 111 seismic stations during the 2017 Pohang earthquake were collected from the National Earthquake Comprehensive Information System (NECIS) of Korea Meteorological Administration (KMA). Figure 1 shows the distribution of 111 stations out of 157 stations in Korea, which provided ground motion records with a high signal-to-noise ratio (SNR). To exclude ground motions with signal distortion due to noise, we only collected recordings with a signal-to-noise ratio (SNR) greater than 2.0. Each station provided three components (North-South, East-West, and Vertical) of ground motions. Thus, the total number of recorded ground motions is $333(=3 \times 111)$.

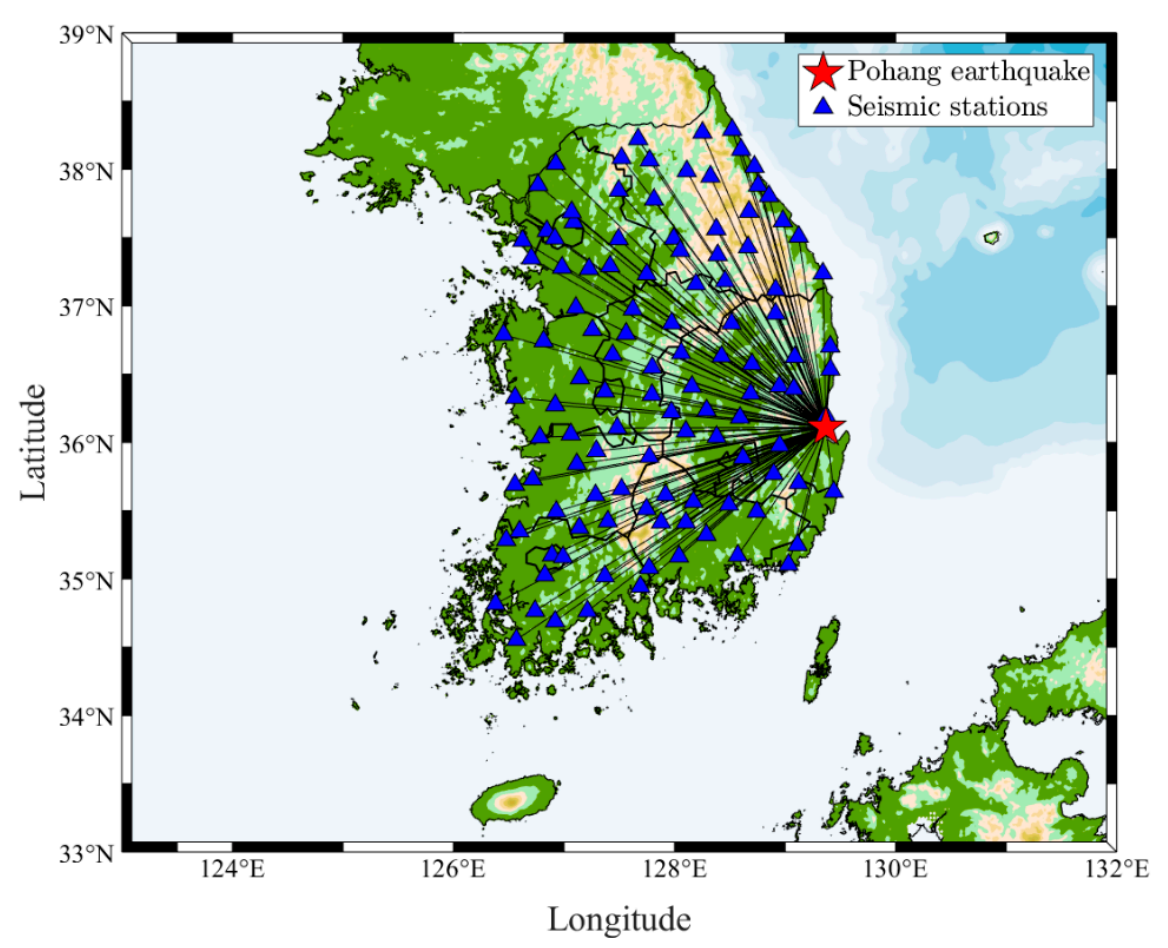

Figure 1. The 2017 Pohang earthquake and seismic recording stations with ray path lines.

All collected ground motions were recorded with a sampling rate of $0.01 \mathrm{~s}$ (100 samples per second), and the NECIS provided these records after applying a high cut anti-aliasing filter to remove the noise with a frequency greater than $40 \mathrm{~Hz}$. In this study, low-frequency noise was also removed by using the $0.1 \mathrm{~Hz}$ (corresponding period $10 \mathrm{~s}$ ) low-cut filter, and baseline correction was done using a technique 
proposed by Papazafeiropoulos and Plevris [13]. Table 1 summarizes the information on the 2017 Pohang earthquake.

Table 1. Information on the 2017 Pohang earthquake (National Earthquake Comprehensive Information System (NECIS)).

\begin{tabular}{cccccc}
\hline Event Name & Local Date-Time & $\begin{array}{c}\text { Longitude } \\
\text { (East) }\end{array}$ & $\begin{array}{c}\text { Latitude } \\
\text { (North) }\end{array}$ & $\begin{array}{c}\text { Focal } \\
\text { Depth } \mathbf{( k m )}\end{array}$ & $\begin{array}{c}\text { Magnitude } \\
\mathbf{M}_{\boldsymbol{L}}\end{array}$ \\
\hline $\begin{array}{c}\text { the 2017 Pohang } \\
\text { earthquake }\end{array}$ & $\begin{array}{c}14: 2915 \text { November, } \\
2017\end{array}$ & 129.37 & 36.11 & 9 & 5.4 \\
\hline
\end{tabular}

Figure 2 shows the East-West $(E-W)$ direction component of ground acceleration $\left(\ddot{u}_{g}\right)$, velocity $\left(\dot{u}_{g}\right)$, and displacement $\left(u_{g}\right)$ at station BUS2. Figure 2a-c show raw record data for ground acceleration, velocity, and displacement. Figure $2 \mathrm{~d}-\mathrm{f}$ show the records after applying a low-pass filter, whereas Figure $2 \mathrm{~g}-\mathrm{i}$ show ground motions after applying base line correction. Figure $2 \mathrm{j}-1$ show ground motions after applying a low-cut filter, as well as base correction. It can be observed that ground motions are properly adjusted by using both a low-cut filter and base correction.
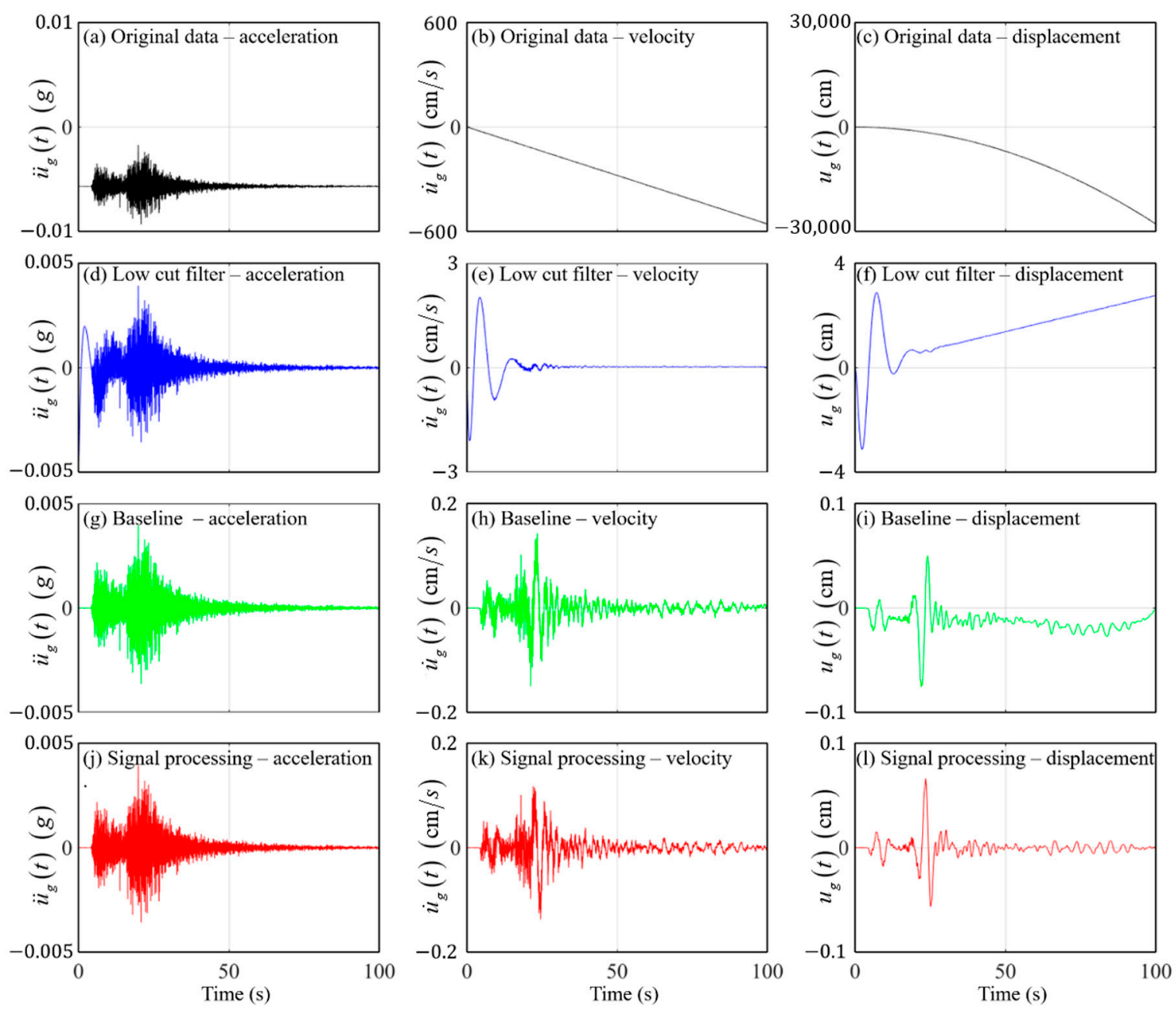

Figure 2. Original and adjusted ground motions at station BUS2: (a) Original data-acceleration, (b) Original data-velocity, (c) Original data-displacement, (d) Low cut filter-acceleration, (e) Low cut filter-velocity, (f) Low cut filter-displacement, (g) Baseline-acceleration, (h) Baseline-velocity, (i) Baseline-displacement, (j) Signal processing-acceleration, (k) Signal processing-velocity, (1) Signal processing-displacement. 
The site amplification effect was also removed from the ground motion records because a ground motion model has been developed for hard rock conditions without considering site effects. In general, site effects are considered in numerical models by applying a site amplification factor to the ground motions generated for hard rock site conditions.

In this study, the site amplification effect was removed from the recorded ground motions by using a horizontal-to-vertical spectral ratio (HVSR) technique, which has been widely used for site amplification factor calculation [14-17].

The site amplification factor, $A M P(f)$, can be calculated from Equation (1).

$$
A M P(f)=\frac{\sqrt{P S A_{E W}(f) \times P S A_{N S}(f)}}{P S A_{V}(f)}
$$

where $P S A_{E W}(f), P S A_{N S}(f)$, and $P S A_{V}(f)$ are the $5 \%$ damped pseudo spectral acceleration (PSA) from the East-West, North-South, and Vertical components of ground motions, respectively. Figure 3 shows the calculated site amplification factor function estimated from the ground motions recorded at stations BUS2, CEA, and CEJA during the 2017 Pohang earthquake. This function was applied to the Fourier spectrum of a ground motion at each frequency. Figure 4 shows the ground acceleration time histories and Fourier spectra before and after applying Equation (1).
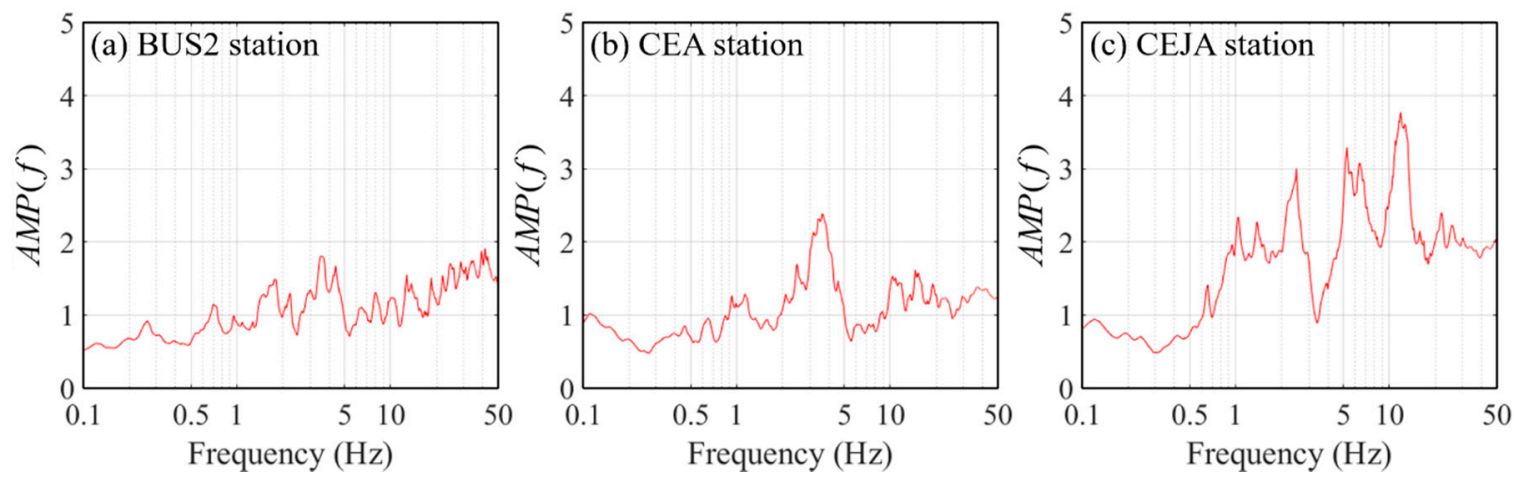

Figure 3. Site amplification factor function from the 2017 Pohang earthquake at sample stations: (a) BUS2 station, (b) CEA station, (c) CEJA station.
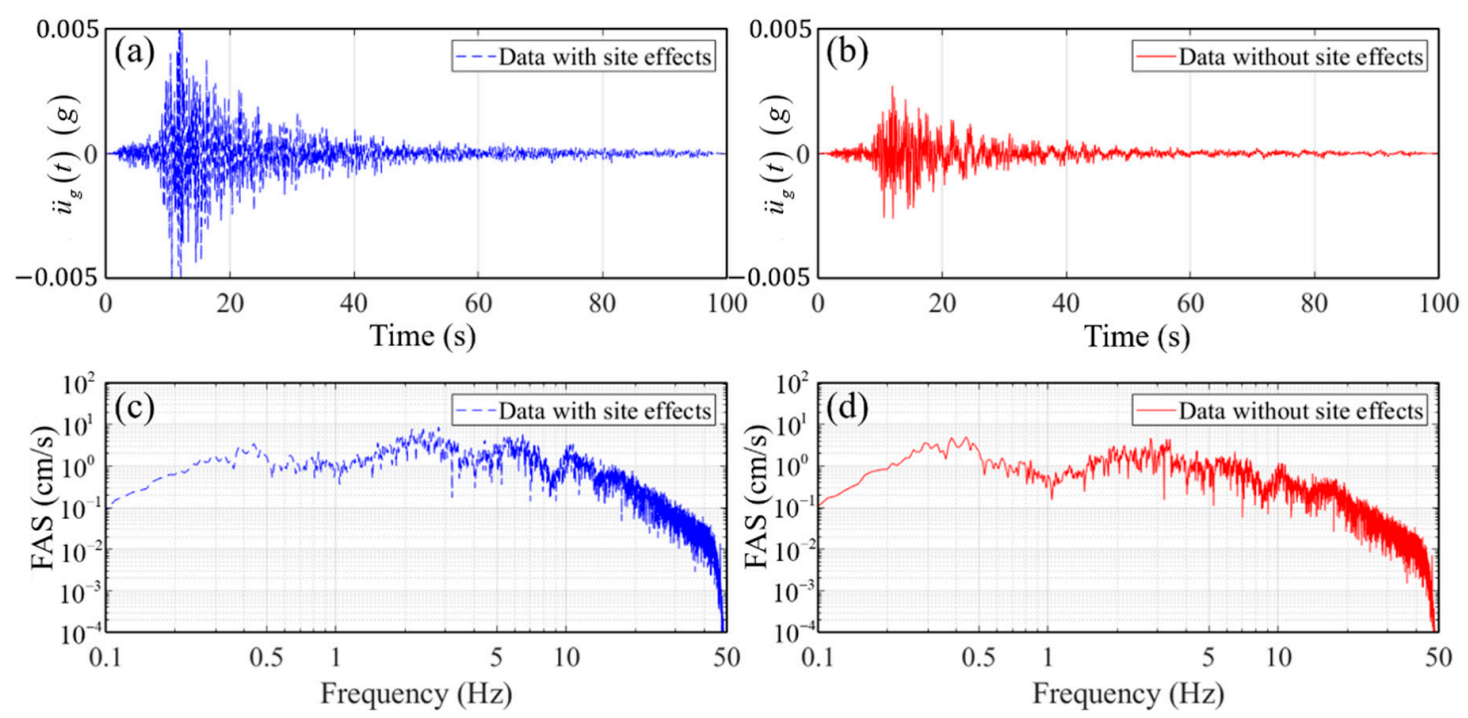

Figure 4. Ground motion recorded at station BUS2 with and without site effects: (a) Ground motion acceleration with site effects, (b) Ground motion acceleration without site effects, (c) Fourier amplitude spectrum with site effects, (d) Fourier amplitude spectrum without site effects. 


\section{Ground Motion Simulation Model}

The numerical model to simulate ground motions in the Korean Peninsula is proposed based on the stochastic point-source model in the frequency domain and the shaping window model in the time domain. The point source model is an effective tool for generating ground motions for a site with limited seismological information.

The Fourier amplitude spectrum (FAS) of a ground motion can be determined using the stochastic point-source model [8-12], which was developed based on the omega-square model [18,19]. This model consists of three main seismological characteristics, namely source, path, and site effects [12].

The shaping window model consists of a ground motion envelope and duration time. Saragoni and Hart [7] proposed the envelope of ground motion records, which was adopted in this study. The duration of a ground motion affects the incidence of the collapse of a structure [20].

\subsection{Stochastic Point-Source Model Estimation}

In the stochastic point-source model, the Fourier amplitude spectrum $[A(f)]$ of a ground motion is calculated using Equation (2).

$$
A(f)=\operatorname{Source}\left(M_{0}, f, f_{c}\right) \times \operatorname{Path}\left(R_{H}, f\right) \times \operatorname{Site}\left(\kappa_{0}, f\right)
$$

where $\operatorname{Source}\left(M_{0}, f, f_{c}\right)$ is the earthquake source effect function, $\operatorname{Path}\left(R_{H}, f\right)$ is the path effect function, $\operatorname{Site}\left(\kappa_{0}, f\right)$ is the site effect function, $M_{0}$ is the seismic moment, $R_{H}$ is the hypocentral distance, $f$ is the frequency, and $f_{c}$ is the corner frequency. A detailed explanation of individual functions is summarized in Table 2.

The component parameters $\kappa_{0}, M_{0}$, and $f_{c}$ to calculate $A(f)$ were estimated from the ground motions recorded at individual stations during the 2017 Pohang earthquake, whereas the values of other component parameters were adopted from previous studies, as listed in Table 2.

To effectively determine the values for $\kappa_{0}, M_{0}$, and $f_{c}$, the $A(f)$ of the recorded ground motions were smoothed using a technique proposed by Konno and Ohmachi [21]. Figure 5 shows the original and smoothed $A(f)$ of ground motions recorded at three sample stations (BUS2, CEA, and CEJA) during the 2017 Pohang earthquake.

Table 2. Information about the functions and component parameters of the stochastic point-source model.

\begin{tabular}{|c|c|c|}
\hline & Functions & Parameters \\
\hline $\begin{array}{l}\text { Source effect } \\
\text { function }\end{array}$ & $\begin{array}{l}\operatorname{Source}\left(M_{0}, f, f_{c}\right) \\
=\frac{M_{o}}{1+\left(f / f_{c}\right)^{2}} \times \frac{\left\langle R_{\theta \phi}\right\rangle \cdot F \cdot V}{4 \pi \rho \beta_{S}^{3}} \times(2 \pi f)^{p} \times \frac{1}{R_{r e f}}\end{array}$ & $\begin{array}{l}\left\langle R_{\theta \phi}\right\rangle(=0.63): \text { S-wave averaged radiation pattern coefficient [22] } \\
F(=2): \text { free surface effect [9] } \\
V(=1 / \sqrt{2}): \text { partition coefficient of a vector into the horizontal component [9] } \\
\rho\left(=2.7 \mathrm{~g} / \mathrm{cm}^{3}\right): \text { near source soil density [23] } \\
\beta_{S}(=3.36 \mathrm{~km} / \mathrm{s}): \text { near source shear wave velocity [23] } \\
p: \text { ground motion type coefficient }(0,1 \text {, and } 2 \text { for displacement, velocity, } \\
\text { and acceleration, respectively) [9] } \\
R_{r e f}(=1 \mathrm{~km}): \text { reference source-to-site distance for seismic source }\end{array}$ \\
\hline $\begin{array}{l}\text { Path effect } \\
\text { function }\end{array}$ & $\begin{array}{l}\operatorname{Path}\left(R_{H}, f\right) \\
=G\left(R_{H}\right) \times \exp \left(-\pi f R_{H} / Q(f) \beta_{s}\right)\end{array}$ & $\begin{array}{l}G\left(R_{H}\right)\left(=\left\{\begin{array}{lr}R_{H}^{-1.3} & \left(R_{H} \leq 70 \mathrm{~km}\right) \\
70^{-1.3} \cdot\left(R_{H} / 70\right)^{0.3} & \left(70 \mathrm{~km}<R_{H} \leq 100 \mathrm{~km}\right) \\
70^{-1.3} \cdot(100 / 70)^{0.3} \cdot\left(R_{H} / 100\right)^{-0.5} & \left(R_{H}>100 \mathrm{~km}\right)\end{array}\right)\right. \\
: \text { geometrical attenuation function [24] } \\
Q(f)\left(=348 f^{0.48}\right): \text { quality factor of the anelastic attenuation function [24] }\end{array}$ \\
\hline
\end{tabular}

In this study, the site attenuation coefficient, $\kappa_{0}$, was determined first. Since the contribution of $\kappa_{0}$ in Equation (2) is determined without interaction with path effect and site amplification, the contribution 
of path effect and site amplification were removed from Equation (2). The Fourier amplitude spectrum without path effect and site amplification $\left[A^{\prime}(f)\right]$ was calculated using Equation (3).

$$
A^{\prime}(f)=\frac{A(f)}{\operatorname{Path}\left(R_{H}, f\right) \times A M P(f)} .
$$

Anderson and Hough [25] estimated the site attenuation coefficient $\left(\kappa_{0}\right)$ using a residual slope of $A(f)^{\prime}$ between $10 \mathrm{~Hz}$ and $40 \mathrm{~Hz}$, which was also used in this study. Figure 6 shows $A(f)$ and $A(f)^{\prime}$. The slope $\left(\kappa_{0}\right)$ of $A(f)^{\prime}$ is also plotted in Figure 6 . The values of $\kappa_{0}$ estimated for individual stations are summarized in Table A1 of Appendix A.
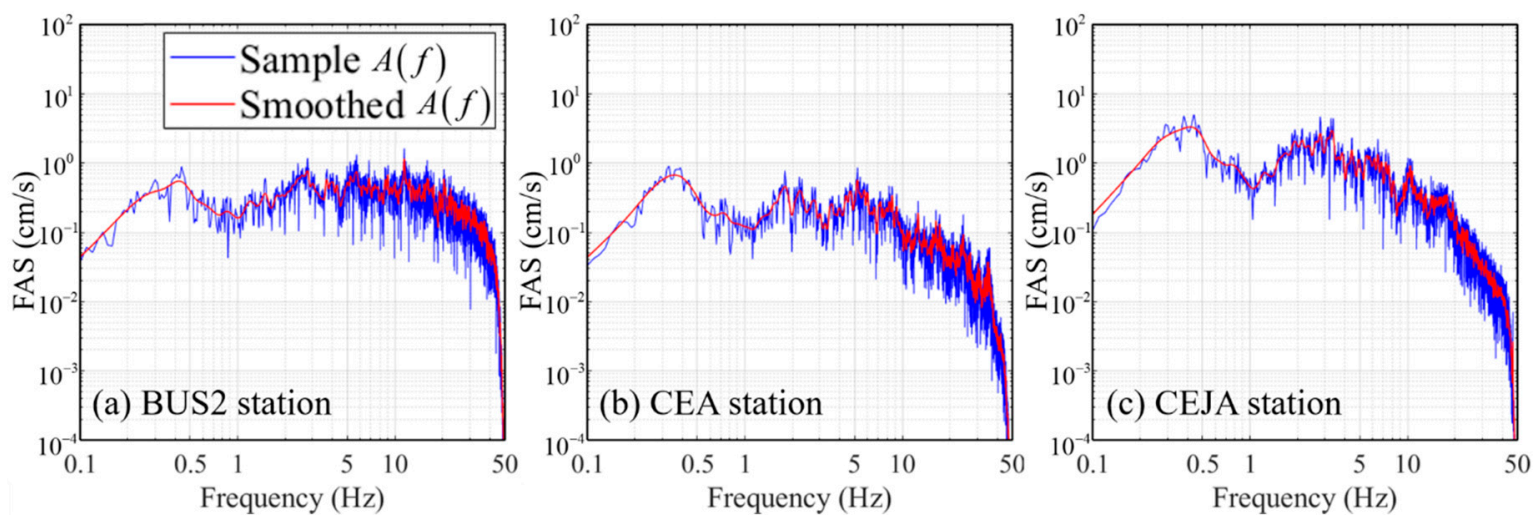

Figure 5. Original and smoothed Fourier amplitude spectrum: (a) BUS2 station, (b) CEA station, (c) CEJA station.
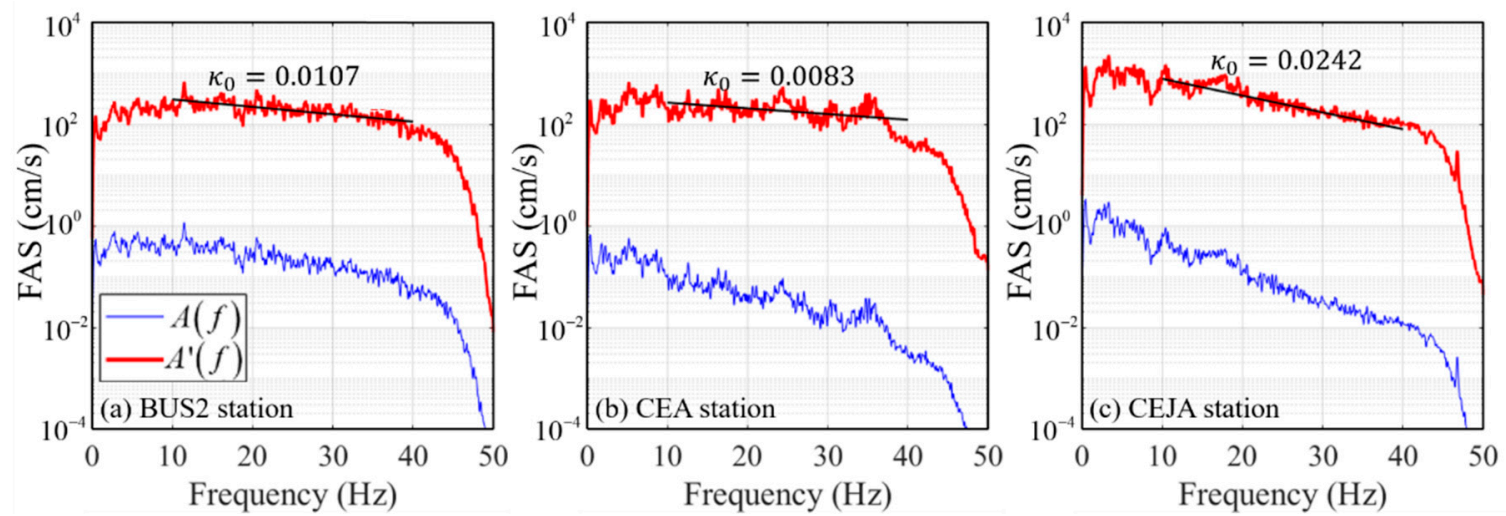

Figure 6. $A(f), A(f)^{\prime}$, and $\kappa_{0}$ values of three sample stations: (a) BUS2 station, (b) CEA station, (c) CEJA station.

Previous studies $[9,26-28]$ estimated $M_{o}$ and $f_{c}$ by using the omega-square model proposed by Brune $[18,19]$ based on the FAS of the recorded ground motions. To determine $M_{o}$ and $f_{\mathcal{c}}$ without interaction with site attenuation $\left(\kappa_{0}\right)$, the Fourier amplitude spectrum without the effect of $\kappa_{0}\left[A^{\prime \prime}(f)\right]$ was calculated using Equation (4). Figure 7 shows $A^{\prime}(f)$ and $A^{\prime \prime}(f)$.

$$
A^{\prime \prime}(f)=\frac{A^{\prime}(f)}{\exp \left(-\pi \kappa_{0} f\right)}
$$

Corner frequency, $f_{c}$, can be estimated using Equations (5)-(8), which were proposed by Andrews [29] and Jo and Baag [27].

$$
f_{c}=\left(\frac{J}{2 \pi^{3} \Omega_{0}^{2}}\right)
$$




$$
\begin{gathered}
\Omega_{0}=2\left(\frac{K^{3}}{J}\right)^{\frac{1}{4}} \\
J=\frac{2}{3}\left(\Omega_{0} \omega_{1}\right)^{2} f_{1}+2 \int_{f_{1}}^{f_{2}}\left|\omega A(\omega)^{\prime \prime}\right|^{2} d f+2\left|\omega_{2} A\left(\omega_{2}\right)^{\prime \prime}\right|^{2} f_{2} \\
K=2\left|\omega_{1} A\left(\omega_{1}\right)^{\prime \prime}\right|^{2} f_{1}+2 \int_{f_{1}}^{f_{2}}\left|A(\omega)^{\prime \prime}\right|^{2} d f+\frac{2}{3}\left|A\left(\omega_{2}\right)^{\prime \prime}\right|^{2} f_{2}
\end{gathered}
$$

Seismic moment, $M_{0}$, can be also calculated from Equation (9), which was proposed by Joshi et al. [28].

$$
M_{0}=\frac{4 \pi \rho \beta_{S}{ }^{3} \times \Omega_{0} \times R_{r e f}}{\left\langle R_{\theta \phi}\right\rangle \times F \times V}
$$
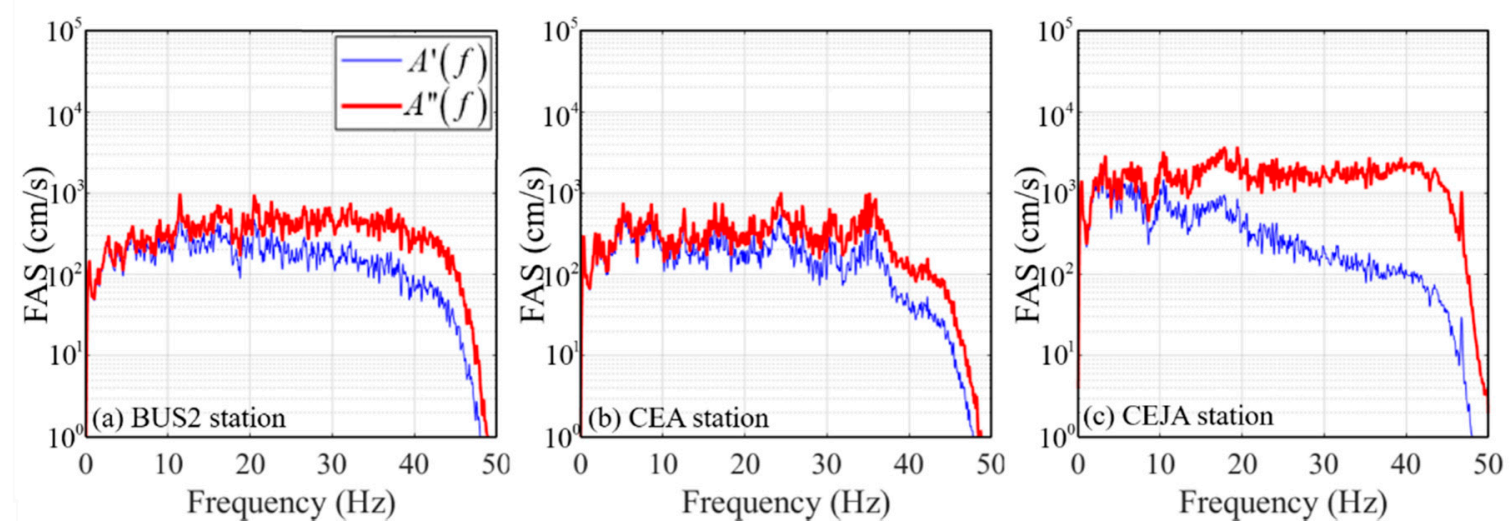

Figure 7. $A^{\prime}(f)$ versus $A^{\prime \prime}(f)$ for three sample stations: (a) BUS2 station, (b) CEA station, (c) CEJA station.

Figure 8 shows the values of $f_{c}$ and $M_{0}$ for 111 stations distributed within the Korean Peninsula. Table A2 in Appendix A lists the values of $f_{c}$ and $M_{0}$ estimated for 111 stations. In this study, the median values $\left(\hat{f}_{c}, \hat{M}_{o}\right)$ of $f_{c}$ and $M_{0}$ were calculated as $0.58 \mathrm{~Hz}$ and $8.39 \times 10^{24}$ dyne-cm, respectively, which were used to calculate $A^{\prime \prime}(f)$ (Equations (2)-(4)). Figure 9 shows the measured and calculated $A^{\prime \prime}(f)$ for three sample stations. It can be observed that the calculated $A^{\prime \prime}(f)$ matches the measured $A^{\prime \prime}(f)$, by which the accuracy of the proposed procedure is verified.
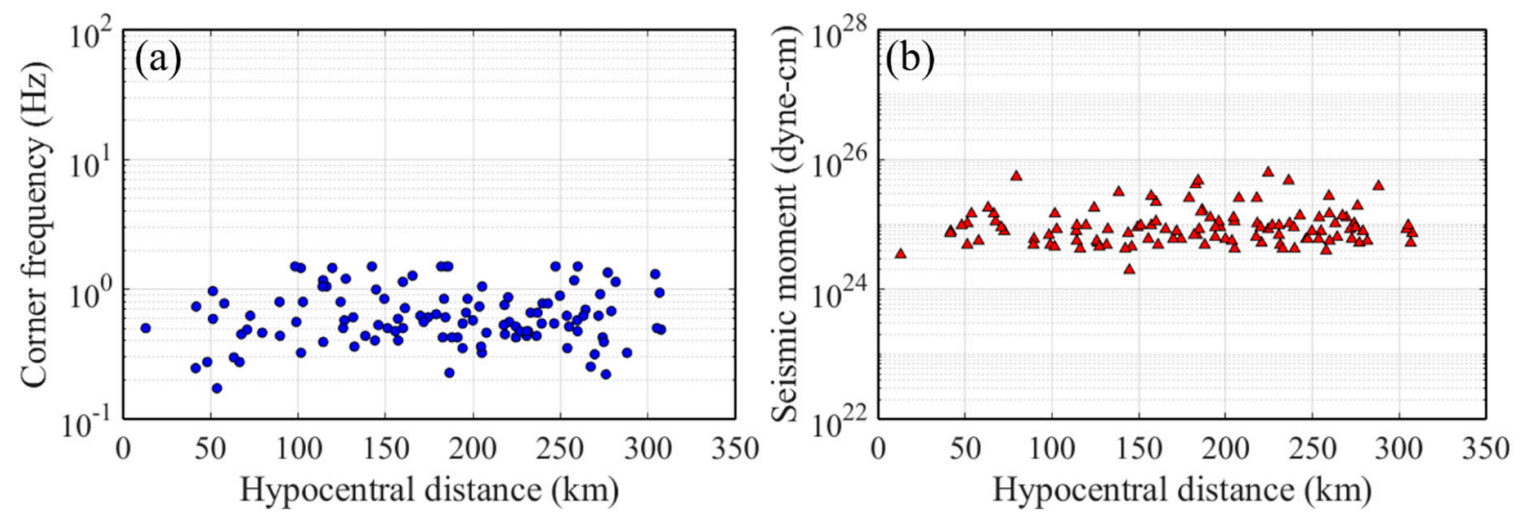

Figure 8. Distributions of the values of $f_{c}$ and $M_{0}$, according to hypocentral distance: (a) Measured corner frequencies at 111 stations, (b) Measured seismic moments at 111 stations. 

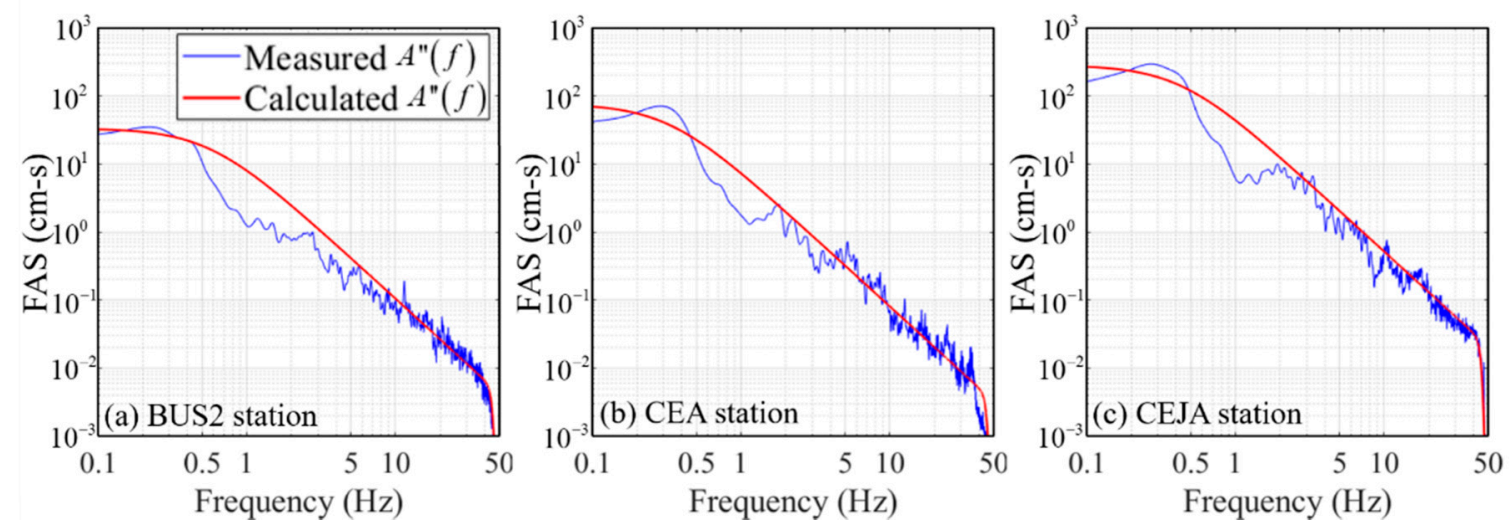

Figure 9. Measured and calculated Fourier amplitude spectrum (FAS) at three sample stations: (a) BUS2 station, (b) CEA station, (c) CEJA station.

\subsection{Shaping Window Model Estimation}

In order to generate a ground acceleration in the time domain $\left(\ddot{u}_{g}(t)\right)$ from $A(f)$, a proper shaping window function should be applied [12]. A shaping window model consists of a ground motion envelope shape and duration time. Boore [12] simulated ground motion recordings using an envelope shape proposed by Saragoni and Hart [7] and a duration time proposed by Atkinson and Boore [11]. However, the shaping window model used by Boore [12] may not properly reflect the envelope shape of the ground motions recorded in the Korean Peninsula. In this study, a shaping window model $(W(t))$ is proposed based on the ground motions recorded during the 2017 Pohang earthquake (Equation (10)).

$$
\ln \left(W\left(t, T_{D}\right)\right)=c_{0}+c_{1} \ln \left(\frac{t}{T_{D}}\right)+c_{2} \frac{t}{T_{D}}
$$

where $t$ is the time, and $T_{D}$ is the duration time. The duration time is calculated from the S-wave arrival time to the time corresponding to the $95 \%$ normalized arias intensity energy $(E(t))$. $E(t)$ is estimated using Equation (11).

$$
E(t)=\frac{\int_{0}^{t} \ddot{u}_{g}^{2}(t) d t}{E_{T}}
$$

where $E_{T}$ is the total energy of $\ddot{u}_{g}(t)$. Figure $10 \mathrm{a}-\mathrm{c}$ show the estimated duration time of a ground motion recorded at the BUS2 station, $E(t)$, and estimated shaping window, respectively. Figure 11 shows the estimated shaping window and duration of ground motions recorded at 111 stations during the 2017 Pohang earthquake. The coefficients $c_{0}, c_{1}$, and $c_{2}$ in Equation (10) are estimated to match the median envelope shape denoted with a thick solid line in Figure 7a.
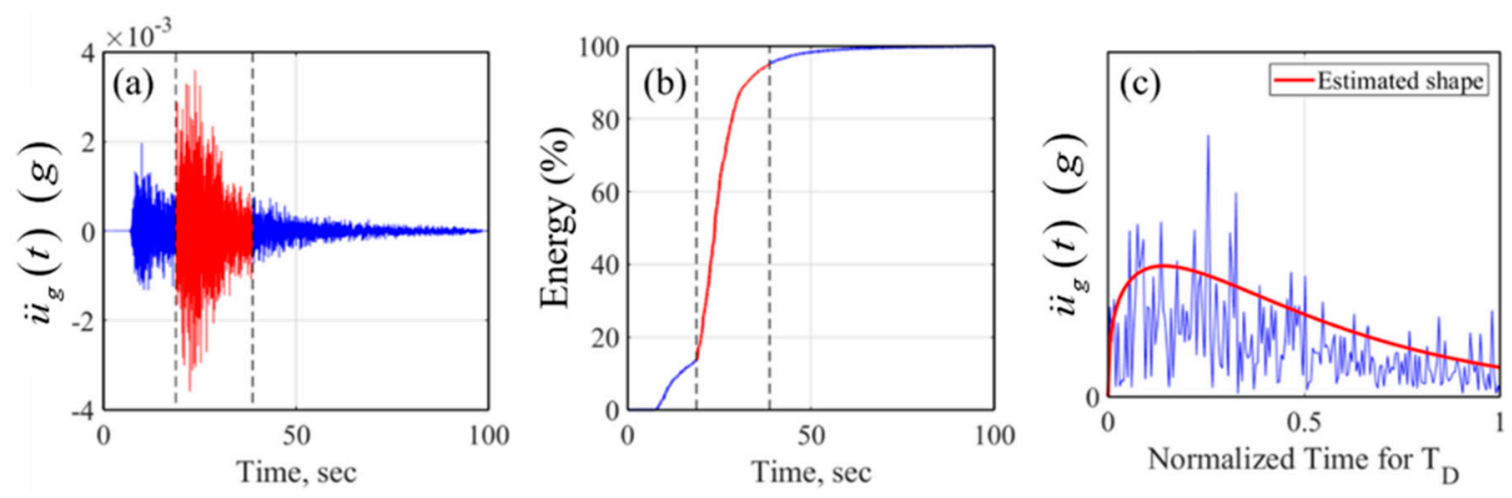

Figure 10. Estimated shaping window and duration at the BUS2 station for the 2017 Pohang earthquake: (a) Ground motion acceleration, (b) Normalized arias intensity, (c) Shaping window. 

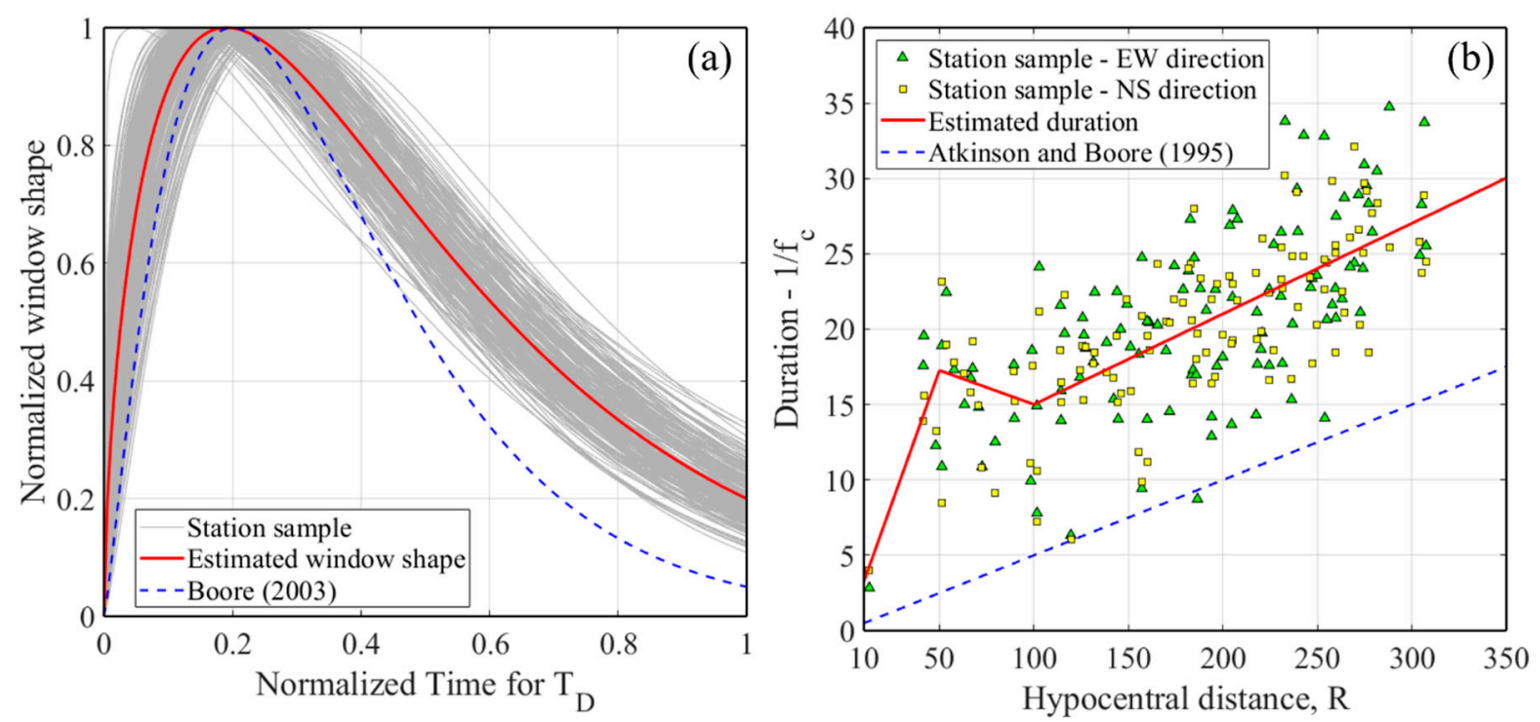

Figure 11. Estimated shaping window and duration for the 2017 Pohang earthquake: (a) Shaping window, (b) Duration with considering corner frequency.

Regression analyses were conducted, by which the values of $c_{0}, c_{1}$, and $c_{2}$ were determined to be $1.6546,0.6227$, and -3.2663 , respectively. The envelope shape obtained from the 2017 Pohang earthquake is significantly different from that calculated using the equations proposed by Boor (2003). The envelope shape constructed from the equation proposed by Boor (2003) significantly underestimates the measured envelope shape of ground motions recorded during the 2017 Pohang earthquake.

Figure $11 \mathrm{~b}$ shows the estimated duration time $\left(T_{D}\right)$ at each station. Previous studies $[10,11,30]$ reported that duration time is mainly affected by corner frequency $\left(f_{c}\right)$ and source-to-site distance $\left(R_{H}\right)$. In this study, the following equation is proposed for $T_{D}$, according to $R_{H}$ and $f_{c}$. Figure $11 \mathrm{~b}$ shows the duration time calculated using Equation (12). This figure also shows that $T_{D}$ calculated from Equation (12) distinctively differs from that calculated using the equations proposed by Atkinson and Boore [11]. The equation of $T_{D}$ developed for the northeastern United States could underestimate $T_{D}$ obtained from the 2017 Pohang earthquake. This observation reveals the importance of why numerical models should be developed for low-to-moderate seismic regions, such as the Korean Peninsula.

$$
T_{D}=\frac{1}{f_{c}}+\left\{\begin{array}{lr}
3.256 & \left(R_{H} \leq 10 \mathrm{~km}\right) \\
-0.247+0.350 R_{\text {hypo }} & \left(10 \mathrm{~km}<R_{H} \leq 50 \mathrm{~km}\right) \\
-19.522-0.045 R_{\text {hypo }} & \left(50 \mathrm{~km}<R_{H} \leq 100 \mathrm{~km}\right) \\
9.005+0.060 R_{\text {hypo }} & \left(R_{H}>100 \mathrm{~km}\right)
\end{array}\right.
$$

\section{Ground Motion Simulation for the 2017 Pohang Earthquake}

Ground motions were generated using the proposed numerical model, consisting of the stochastic point-source model and shaping window model. The procedure is briefly summarized as follows:

(1) White noise is first generated in time domain for a duration time of the ground motion (Equation (12)).

(2) The noise is then windowed using the shaping window model (Equation (10)).

(3) The windowed noise is transformed into the frequency domain.

(4) The $A(f)$ of the noise is normalized by the square-root of the mean square of $A(f)$ in all frequencies.

(5) The normalized $A(f)$ is then multiplied by the stochastic simulation model (Equation (2)).

(6) The resulting $A(f)$ is transformed back to the time domain, which is a simulated ground motion.

Figure 12a,b show two horizontal components' ground motions at station BUS2 during the 2017 Pohang earthquake, whereas Figure 12c presents one ground motion simulated using the proposed 
procedure. Figure $12 \mathrm{~d}$ presents the geomean of $A(f)$ for recorded ground motions. In this figure, $A(f)$ calculated using Equation (2) is also included, which shows that the calculated $A(f)$ matches that obtained from recorded ground motions. Figure 12e shows the geomean of $5 \%$ damped-pseudo spectral acceleration $P S A(T)$ and the median $P S A(T)$ values of 1000 simulated ground motions. The difference in $P S A(T)$ between recorded and simulated ground motions is generally small. Similar observations were made for the ground motions for stations CEA and CEJA.
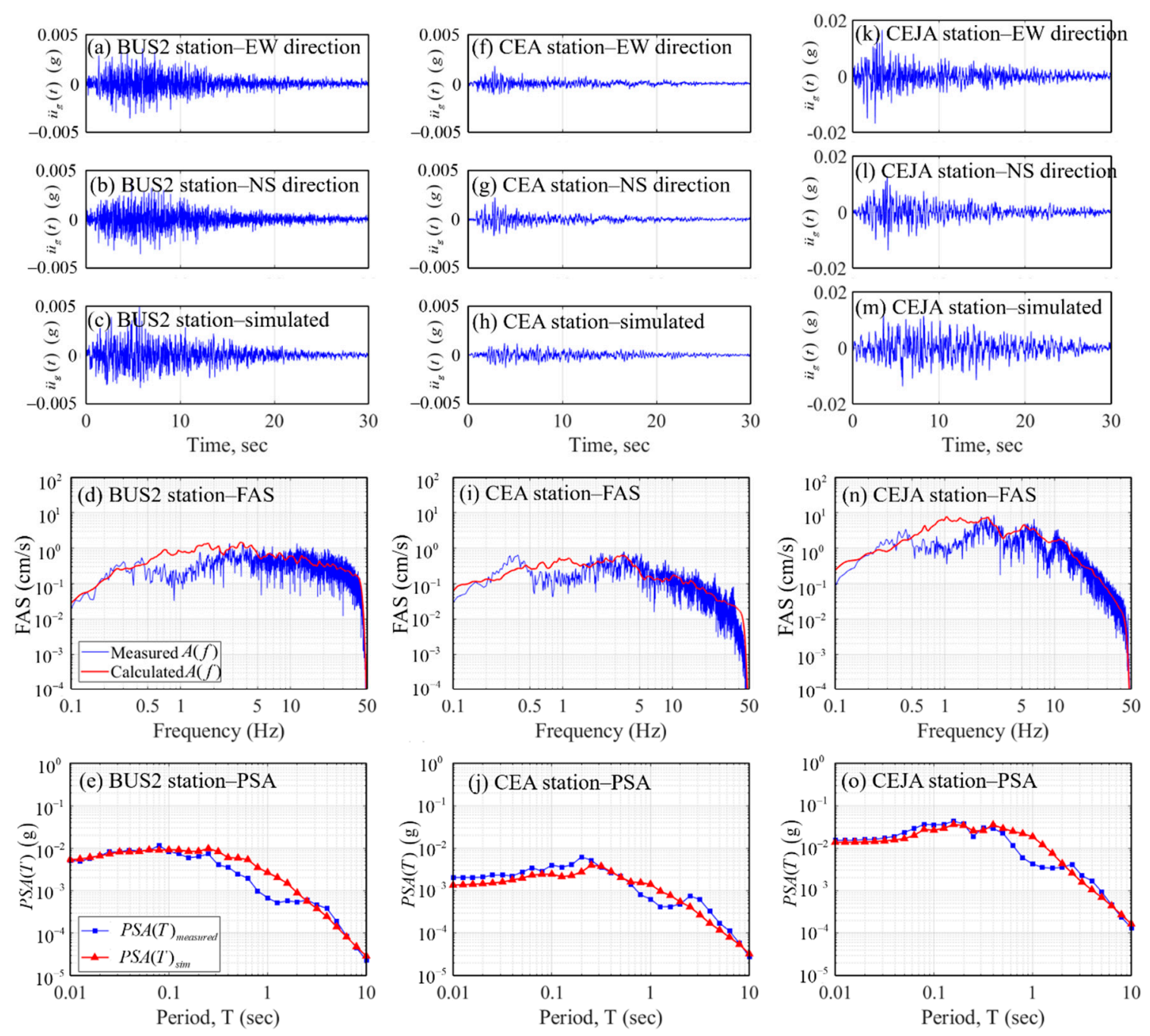

Figure 12. Recorded and simulated ground motion at sample stations: (a) BUS2 station-EW direction, (b) BUS2 station-NS direction, (c) BUS2 station-simulated, (d) BUS2 station-FAS, (e) BUS2 station-PSA, (f) CEA station-EW direction, (g) CEA station-NS direction, (h) CEA station-simulated, (i) CEA station-FAS, (j) CEA station-PSA, (k) CEJA station-EW direction, (1) CEJA station-NS direction, (m) CEJA station-simulated, (n) CEJA station-FAS, (o) CEJA station-PSA.

To verify the accuracy of the proposed numerical model, ground motions were simulated at 111 stations for the 2017 Pohang earthquake and their PSA $(T)$ values were calculated. Residuals induced by the difference in simulated and recorded $P S A(T)\left(P S A(T)_{\text {sim }} P S A(T)_{\text {measured }}\right)$ were calculated using Equation (13), with a period $(T)$ range between $0.01 \mathrm{~s}$ and $10 \mathrm{~s}$.

$$
\operatorname{Residual}(T)=\log \left[P S A(T)_{\text {sim }}\right]-\log \left[\operatorname{PSA}(T)_{\text {measured }}\right]
$$

Residuals were calculated for all ground motions of the 111 stations. Figure 13 shows the residuals according to hypocentral distance. As shown in Figure 13a, the mean value of residuals is near zero, 
which indicates that the ground motions in the Korean Peninsula can be adequately simulated using the proposed numerical model with the source, path effect, and site amplification functions.
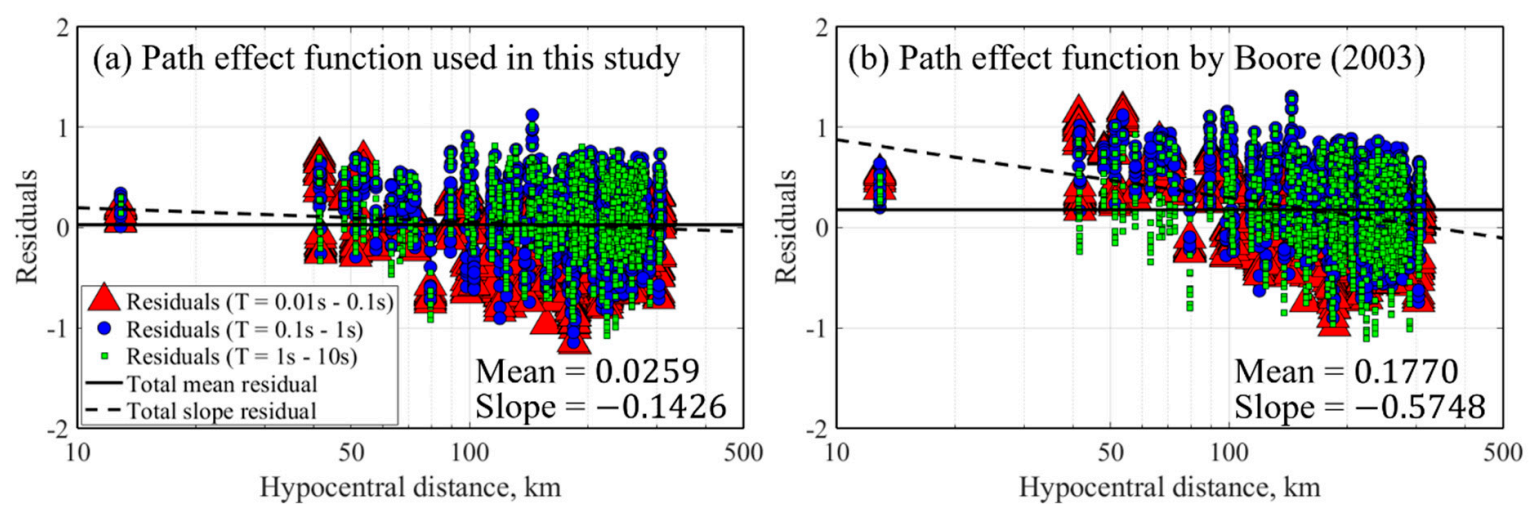

Figure 13. Estimated residuals, mean residual, and slope residual at various periods for the 2017 Pohang earthquake: (a) Path effect function used in this study, (b) Path effect function by Boore (2003).

If the path effect function proposed by Boor (2003) is used in the numerical model, the mean residual deviates from zero, as shown in Figure 13b. The degree of deviation varies according to the period. In the case of using the source function and site amplification function proposed by others when simulating ground motions with the proposed numerical model, similar observations were made, which are not included in the paper.

\section{Conclusions}

In this study, a numerical model was proposed to simulate ground motions in the Korean Peninsula. The model consisted of a stochastic point-source model and a shaping window model developed based on ground motions recorded at 111 stations during the 2017 Pohang earthquake. Conclusions obtained from this study are as follows:

(1) Source, path, and site effect functions were developed for the stochastic point-source model, which reflected the seismological characteristics of the Korean Peninsula.

(2) To generate ground motions in the time domain that represents ground motions recorded in the Korean Peninsula, an envelope shape and a duration time function were proposed based on the ground motions recorded at 111 stations.

(3) In order to verify the accuracy of the proposed numerical model, residuals measuring the difference in $P S A(T)$ between recorded and simulated ground motions were calculated for 111 stations. It was observed that ground motions in the Korean Peninsula were simulated accurately using the proposed numerical model, which included proper source, path, and site effect functions.

(4) The results of this study reveal the potential of the proposed numerical model to simulate input ground motions for low-to-moderate seismic regions, such as the Korean Peninsula.

Author Contributions: Methodology, S.W.H.; investigation, H.W.J. All authors have read and agreed to the published version of the manuscript.

Funding: This research was funded by the Korea Agency for Infrastructure Technology Advancement, grant number 20CTAP-C152179-02.

Acknowledgments: This research was supported by grants from the Korea Agency for Infrastructure Technology (20CTAP-C152179-02).

Conflicts of Interest: The authors declare no conflict of interest. 


\section{Appendix A}

Table A1. $\kappa_{0}$ values for 111 stations.

\begin{tabular}{|c|c|c|c|c|c|c|c|c|c|c|c|}
\hline No. & Station & $\kappa_{0}$ & No. & Station & $\kappa_{0}$ & No. & Station & $\kappa_{0}$ & No. & Station & $\kappa_{0}$ \\
\hline 1 & ADO2 & 0.0092 & 29 & GOCB & 0.0203 & 57 & JEU2 & -0.0035 & 85 & SCHA & 0.0161 \\
\hline 2 & ADOA & 0.0284 & 30 & GSG & -0.0112 & 58 & JINA & 0.0197 & 86 & SEHB & 0.0259 \\
\hline 3 & $\mathrm{BON}$ & 0.0182 & 31 & GUM & 0.0447 & 59 & JMJ & 0.0149 & 87 & $\mathrm{SEO} 2$ & 0.0059 \\
\hline 4 & BOSB & 0.0150 & 32 & GUS & 0.0017 & 60 & JNPA & 0.0221 & 88 & SES2 & 0.0132 \\
\hline 5 & BSA & 0.0208 & 33 & GUWB & 0.0235 & 61 & JUR & 0.0120 & 89 & SHHB & 0.0149 \\
\hline 6 & BURB & 0.0254 & 34 & GWJ & 0.0289 & 62 & KAWA & 0.0227 & 90 & SKC2 & 0.0102 \\
\hline 7 & BUS & 0.0107 & 35 & GWYB & 0.0142 & 63 & $\mathrm{KCH} 2$ & 0.0312 & 91 & SMKB & 0.0267 \\
\hline 8 & BUYB & 0.0093 & 36 & HAC & 0.0226 & 64 & KMSA & 0.0234 & 92 & SUCA & 0.0149 \\
\hline 9 & CEA & 0.0083 & 37 & HAD & 0.0352 & 65 & KOJ2 & 0.0241 & 93 & SWO & 0.0255 \\
\hline 10 & CEJA & 0.0242 & 38 & HALB & 0.0253 & 66 & KWJ2 & 0.0112 & 94 & TBA2 & 0.0352 \\
\hline 11 & $\mathrm{CHC} 2$ & 0.0161 & 39 & HANB & 0.0150 & 67 & MAS2 & 0.0087 & 95 & TEJ2 & 0.0370 \\
\hline 12 & $\mathrm{CHJ} 2$ & 0.0111 & 40 & HCNA & 0.0245 & 68 & MGY2 & 0.0177 & 96 & TOHA & 0.0183 \\
\hline 13 & $\mathrm{CHO}$ & 0.0253 & 41 & HES & 0.0167 & 69 & MIYA & 0.0287 & 97 & ULJ2 & 0.0118 \\
\hline 14 & CHR & 0.0254 & 42 & HWCA & 0.0192 & 70 & MOP & 0.0218 & 98 & USN2 & 0.0275 \\
\hline 15 & CHYB & 0.0219 & 43 & HWCB & 0.0251 & 71 & MUS2 & 0.0261 & 99 & WJU2 & 0.0472 \\
\hline 16 & CIGB & 0.0160 & 44 & ICN & 0.0131 & 72 & NAJ & 0.0186 & 100 & YAPA & 0.0208 \\
\hline 17 & CPR2 & 0.0077 & 45 & IJA2 & 0.0197 & 73 & NAWB & 0.0122 & 101 & YAY & 0.0227 \\
\hline 18 & $\mathrm{CSO}$ & 0.0277 & 46 & IJAA & 0.0235 & 74 & NOW & -0.0065 & 102 & YAYA & 0.0242 \\
\hline 19 & CWO2 & 0.0096 & 47 & IKSA & 0.0140 & 75 & OKCB & 0.0109 & 103 & YCH & 0.0179 \\
\hline 20 & DAG2 & 0.0197 & 48 & IMSA & 0.0235 & 76 & OKEB & 0.0269 & 104 & YEG & 0.0051 \\
\hline 21 & DAU & 0.0061 & 49 & IMWB & 0.0205 & 77 & PHA2 & 0.0130 & 105 & YEYB & 0.0190 \\
\hline 22 & DGY2 & 0.0055 & 50 & INCA & 0.0125 & 78 & PORA & 0.0216 & 106 & YINB & 0.0344 \\
\hline 23 & DUSB & 0.0121 & 51 & JAHA & 0.0288 & 79 & PTK & 0.0113 & 107 & YNCB & 0.0214 \\
\hline 24 & EMSB & 0.0279 & 52 & JASA & 0.0162 & 80 & PUAA & 0.0182 & 108 & YOA & 0.0140 \\
\hline 25 & EURB & 0.0130 & 53 & JECB & 0.0122 & 81 & PYC & 0.0237 & 109 & YOCB & 0.0058 \\
\hline 26 & EUSB & 0.0212 & 54 & JEJB & 0.0162 & 82 & PYCA & 0.0199 & 110 & YODB & 0.0222 \\
\hline 27 & GAPB & 0.0288 & 55 & JEO2 & 0.0021 & 83 & SACA & 0.0155 & 111 & YOJB & 0.0170 \\
\hline 28 & GIC & 0.0110 & 56 & JES & 0.0340 & 84 & SAJ & 0.0227 & \multicolumn{2}{|c|}{ Median } & 0.0192 \\
\hline
\end{tabular}

Table A2. Calculated corner frequency and seismic moment at all stations used in this study.

\begin{tabular}{|c|c|c|c|c|c|c|c|c|c|c|c|}
\hline No. & $\begin{array}{l}f_{c^{\prime}} \\
\mathbf{H z}\end{array}$ & $\begin{array}{c}M_{0}, \\
\text { Dyne-cm }\end{array}$ & No. & $\begin{array}{l}f_{c^{\prime}} \\
\mathrm{Hz}\end{array}$ & $\begin{array}{c}M_{0}, \\
\text { Dyne-cm }\end{array}$ & No. & $\begin{array}{l}f_{c^{\prime}} \\
\mathrm{Hz}\end{array}$ & $\begin{array}{c}M_{0} \\
\text { Dyne-cm }\end{array}$ & No. & $\begin{array}{l}f_{c^{\prime}} \\
\mathrm{Hz}\end{array}$ & $\begin{array}{c}M_{0} \\
\text { Dyne-cm }\end{array}$ \\
\hline 1 & 0.59 & $1.03 \times 10^{25}$ & 29 & 0.70 & $6.37 \times 10^{24}$ & 57 & 0.44 & $6.82 \times 10^{24}$ & 85 & 0.76 & $2.53 \times 10^{25}$ \\
\hline 2 & 0.46 & $5.42 \times 10^{25}$ & 30 & 0.22 & $1.92 \times 10^{25}$ & 58 & 0.50 & $2.21 \times 10^{25}$ & 86 & 0.48 & $1.46 \times 10^{25}$ \\
\hline 3 & 0.84 & $8.99 \times 10^{24}$ & 31 & 1.42 & $6.82 \times 10^{24}$ & 59 & 0.36 & $1.27 \times 10^{25}$ & 87 & 0.25 & $1.36 \times 10^{25}$ \\
\hline 4 & 0.55 & $5.94 \times 10^{24}$ & 32 & 0.66 & $4.21 \times 10^{24}$ & 60 & 0.64 & $2.53 \times 10^{25}$ & 88 & 0.63 & $8.39 \times 10^{24}$ \\
\hline 5 & 1.05 & $4.21 \times 10^{24}$ & 33 & 0.49 & $8.99 \times 10^{24}$ & 61 & 0.63 & $1.03 \times 10^{25}$ & 89 & 0.39 & $8.99 \times 10^{24}$ \\
\hline 6 & 0.43 & $1.27 \times 10^{25}$ & 34 & 1.46 & $5.94 \times 10^{24}$ & 62 & 0.55 & $8.99 \times 10^{24}$ & 90 & 0.35 & $1.27 \times 10^{25}$ \\
\hline 7 & 0.56 & $4.83 \times 10^{24}$ & 35 & 0.58 & $5.94 \times 10^{24}$ & 63 & 1.37 & $4.21 \times 10^{24}$ & 91 & 1.17 & $3.93 \times 10^{24}$ \\
\hline 8 & 0.56 & $5.17 \times 10^{24}$ & 36 & 0.44 & $3.12 \times 10^{25}$ & 64 & 0.63 & $5.94 \times 10^{24}$ & 92 & 0.53 & $6.37 \times 10^{24}$ \\
\hline 9 & 0.32 & $1.11 \times 10^{25}$ & 37 & 1.43 & $8.39 \times 10^{24}$ & 65 & 0.74 & $5.54 \times 10^{24}$ & 93 & 0.89 & $7.83 \times 10^{24}$ \\
\hline 10 & 0.43 & $4.11 \times 10^{25}$ & 38 & 0.72 & $4.83 \times 10^{24}$ & 66 & 0.78 & $4.21 \times 10^{24}$ & 94 & 1.46 & $9.64 \times 10^{24}$ \\
\hline 11 & 0.48 & $4.83 \times 10^{24}$ & 39 & 0.49 & $7.31 \times 10^{24}$ & 67 & 1.21 & $4.51 \times 10^{24}$ & 95 & 1.29 & $6.82 \times 10^{24}$ \\
\hline 12 & 0.50 & $9.64 \times 10^{24}$ & 40 & 0.80 & $1.79 \times 10^{25}$ & 68 & 0.36 & $8.39 \times 10^{24}$ & 96 & 0.59 & $2.72 \times 10^{25}$ \\
\hline 13 & 1.05 & $4.21 \times 10^{24}$ & 41 & 0.84 & $8.99 \times 10^{24}$ & 69 & 0.80 & $4.83 \times 10^{24}$ & 97 & 0.28 & $1.46 \times 10^{25}$ \\
\hline 14 & 1.46 & $4.51 \times 10^{24}$ & 42 & 0.58 & $2.72 \times 10^{25}$ & 70 & 0.94 & $5.17 \times 10^{24}$ & 98 & 0.97 & $4.83 \times 10^{24}$ \\
\hline 15 & 0.32 & $1.46 \times 10^{25}$ & 43 & 0.68 & $7.83 \times 10^{24}$ & 71 & 1.31 & $8.39 \times 10^{24}$ & 99 & 1.37 & $1.56 \times 10^{25}$ \\
\hline 16 & 0.44 & $5.94 \times 10^{24}$ & 44 & 0.45 & $1.03 \times 10^{25}$ & 72 & 1.23 & $5.54 \times 10^{24}$ & 100 & 0.48 & $9.64 \times 10^{24}$ \\
\hline 17 & 0.58 & $5.17 \times 10^{24}$ & 45 & 0.66 & $1.03 \times 10^{25}$ & 73 & 0.35 & $6.37 \times 10^{24}$ & 101 & 0.87 & $8.99 \times 10^{24}$ \\
\hline 18 & 0.74 & $7.83 \times 10^{24}$ & 46 & 0.43 & $6.22 \times 10^{25}$ & 74 & 0.32 & $1.27 \times 10^{25}$ & 102 & 0.44 & $4.72 \times 10^{25}$ \\
\hline 19 & 0.43 & $1.03 \times 10^{25}$ & 47 & 0.46 & $2.53 \times 10^{25}$ & 75 & 0.40 & $7.31 \times 10^{24}$ & 103 & 0.80 & $8.39 \times 10^{24}$ \\
\hline 20 & 0.78 & $5.54 \times 10^{24}$ & 48 & 0.66 & $1.11 \times 10^{25}$ & 76 & 0.56 & $7.83 \times 10^{24}$ & 104 & 1.34 & $5.17 \times 10^{24}$ \\
\hline 21 & 0.63 & $7.83 \times 10^{24}$ & 49 & 0.50 & $5.54 \times 10^{24}$ & 77 & 0.50 & $3.42 \times 10^{24}$ & 105 & 0.30 & $1.79 \times 10^{25}$ \\
\hline 22 & 0.23 & $1.67 \times 10^{25}$ & 50 & 0.32 & $3.84 \times 10^{25}$ & 78 & 0.63 & $5.94 \times 10^{24}$ & 106 & 0.48 & $9.64 \times 10^{24}$ \\
\hline 23 & 0.53 & $4.51 \times 10^{24}$ & 51 & 0.92 & $5.94 \times 10^{24}$ & 79 & 0.52 & $8.39 \times 10^{24}$ & 107 & 0.50 & $9.64 \times 10^{24}$ \\
\hline 24 & 0.84 & $6.82 \times 10^{24}$ & 52 & 0.61 & $5.94 \times 10^{24}$ & 80 & 0.78 & $1.36 \times 10^{25}$ & 108 & 1.14 & $5.54 \times 10^{24}$ \\
\hline 25 & 0.61 & $4.83 \times 10^{24}$ & 53 & 0.40 & $9.64 \times 10^{24}$ & 81 & 1.27 & $8.39 \times 10^{24}$ & 109 & 0.25 & $7.31 \times 10^{24}$ \\
\hline 26 & 0.45 & $1.11 \times 10^{25}$ & 54 & 0.17 & $1.46 \times 10^{25}$ & 82 & 0.61 & $4.72 \times 10^{25}$ & 110 & 0.28 & $9.64 \times 10^{24}$ \\
\hline 27 & 0.52 & $7.83 \times 10^{24}$ & 55 & 0.43 & $4.83 \times 10^{24}$ & 83 & 0.48 & $5.94 \times 10^{24}$ & 111 & 0.39 & $9.64 \times 10^{24}$ \\
\hline 28 & 1.17 & $5.54 \times 10^{24}$ & 56 & 1.14 & $1.11 \times 10^{25}$ & 84 & 1.05 & $7.83 \times 10^{24}$ & \multicolumn{2}{|c|}{ Median 0.58} & $8.39 \times 10^{24}$ \\
\hline
\end{tabular}




\section{References}

1. Johnston, A.C. Seismic Moment Assessment of Earthquakes in Stable Continental Regions-I. Instrumental Seismicity. Geophys. J. Int. 1996, 124, 381-414. [CrossRef]

2. Schulte, S.M.; Mooney, W.D. An Updated Global Earthquake Catalogue for Stable Continental Regions: Reassessing the Correlation with Ancient Rifts. Geophys. J. Int. 2005, 161, 707-721. [CrossRef]

3. Lee, K.; Yang, W.S. Historical Seismicity of Korea. Bull. Seismol. Soc. Am. 2006, 96, 846-855. [CrossRef]

4. Wen, Y.K.; Collins, K.R.; Han, S.W.; Elwood, K.J. Dual-level designs of buildings under seismic loads. Struct. Saf. 1996, 18, 195-224. [CrossRef]

5. Lee, L.H.; Lee, H.H.; Han, S.W. Method of selecting design earthquake ground motions for tall buildings. Struct. Des. Tall. Spec. 2000, 9, 201-213. [CrossRef]

6. Han, S.W.; Seok, S.W. Efficient Procedure for Selecting and Scaling Ground Motions for Response History Analysis. J. Struct. Eng. 2014, 140, 06013004. [CrossRef]

7. Saragoni, G.; Hart, G. Simulation of Artificial Earthquakes. Earthq. Eng. Struct. Dyn. 1974, 2, $249-267$. [CrossRef]

8. Hanks, T.C.; McGuire, R.K. The Character of High-frequency Strong Ground Motion. Bull. Seismol. Soc. Am. 1981, 71, 2071-2095.

9. Boore, D.M. Stochastic Simulation of High-frequency Ground Motions Based on Seismological Models of the Radiated Spectra. Bull. Seismol. Soc. Am. 1983, 73, 1865-1894.

10. Boore, D.M.; Atkinson, G.M. Stochastic Prediction of Ground Motion and Spectral Response Parameters at Hard-rock Sites in Eastern North America. Bull. Seismol. Soc. Am. 1987, 77, 440-467.

11. Atkinson, G.M.; Boore, D.M. Ground-motion Relations for Eastern North America. Bull. Seismol. Soc. Am. 1995, 85, 17-30.

12. Boore, D.M. Simulation of Ground Motion Using the Stochastic Method. Pure. Appl. Geophys. 2003, 160, 635-676. [CrossRef]

13. Papazafeiropoulos, G.; Plevris, V. OpenSeismoMatlab: A New Open-source Software for Strong Ground Motion Data Processing. Heliyon 2018, 4, e00784. [CrossRef] [PubMed]

14. Nakamura, Y. A Method for Dynamic Characteristics Estimation of Subsurface Using Microtremor on the Ground Surface. Q. Rep. Railw. Tech. Res. Inst. 1989, 30, 25-33.

15. Atkinson, G.M.; Cassidy, J.F. Integrated Use of Seismograph and Strong-Motion Data to Determine Soil Amplification: Response of the Fraser River Delta to the Duvall and Georgia Strait Earthquakes. Bull. Seismol. Soc. Am. 2000, 90, 1028-1040. [CrossRef]

16. Zhao, J.X.; Irikura, K.; Zhang, J.; Yoshimitsu, F.; Somerville, P.G.; Asano, A.; Ohno, Y.; Oouchi, T.; Takahashi, T.; Ogawa, H. An Empirical Site-Classification Method for Strong-Motion Stations in Japan Using H/V Response Spectral Ratio. Bull. Seismol. Soc. Am. 2006, 96, 914-925. [CrossRef]

17. Zandieh, A.; Pezeshk, S. Investigation of Geometrical Spreading and Quality Factor Functions in the New Madrid Seismic Zone. Bull. Seismol. Soc. Am. 2010, 100, 2185-2195. [CrossRef]

18. Brune, J. Tectonic Stress and the Spectra of Seismic Shear Waves. J. Geophys. Res. 1970, 75, 4997-5009. [CrossRef]

19. Brune, J. Correction: Tectonic Stress and the Spectra of Seismic Shear Waves. J. Geophys. Res. 1971, 76, 5002.

20. Chandramohan, R.; Baker, J.W.; Deierlein, G.G. Quantifying the Influence of Ground Motion Duration on Structural Collapse Capacity Using Spectrally Equivalent Records. Earthq. Spectra 2016, 32, 927-950. [CrossRef]

21. Konno, K.; Ohmachi, T. Ground-Motion Characteristics Estimated from Spectral Ratio between Horizontal and Vertical Components of Microtremor. Bull. Seismol. Soc. Am. 1998, 88, 228-241.

22. Boore, D.M.; Boatwright, J. Average Body-wave Radiation Coefficients. Bull. Seismol. Soc. Am. 1984, 74, 1615-1621.

23. Kim, S.K. A Study on the Crustal Structure of the Korean Peninsula. J. Geol. Soc. Korea 1995, 8, $393-403$.

24. Jee, H.W.; Han, S.W. Equations of Path Effects to Simulate Ground Motions in Korean Peninsula Using Point-source Model. In Proceedings of the The 2019 World Congress on Advances in Structural Engineering and Mechanics (ASEM19), Jeju, Korea, 17-21 September 2019.

25. Anderson, J.G.; Hough, S.E. A Model for the Shape of the Fourier Amplitude Spectrum of Acceleration at High Frequencies. Bull. Seismol. Soc. Am. 1984, 74, 1969-1993. 
26. Atkinson, G.M.; Boore, D.M. Evaluation of Models for Earthquake Source Spectra in Eastern North America. Bull. Seismol. Soc. Am. 1998, 88, 917-934.

27. Jo, N.D.; Baag, C.E. Stochastic Prediction of Strong Ground Motions in Southern Korea. J. Earthq. Eng. Soc. Korea 2001, 5, 17-26.

28. Joshi, A.; Tomer, M.; Lal, S.; Chopra, S.; Singh, S.; Prajapati, S.; Sharma, M.L.; Sandeep. Estimation of the Source Parameters of the Nepal Earthquake from Strong Motion Data. Nat. Hazards. 2016, 83, 867-883. [CrossRef]

29. Andrews, D.J. Objective Determination of Source Parameters and Similarity of Earthquakes of Different Size. Earthq. Source Mech. 1986, 37, 259-267.

30. Boatwright, J.; Choy, G.L. Acceleration source spectra anticipated for large earthquakes in northeastern North America. Bull. Seismol. Soc. Am. 1992, 82, 660-682.

(C) 2020 by the authors. Licensee MDPI, Basel, Switzerland. This article is an open access article distributed under the terms and conditions of the Creative Commons Attribution (CC BY) license (http://creativecommons.org/licenses/by/4.0/). 